\title{
Accumulation of intramuscular toxic lipids, a link between fat mass accumulation and sarcopenia ${ }^{\text {th }}$
}

\author{
Frederic Capel*, Alexandre Pinel and Stéphane Walrand \\ Unité de Nutrition Humaine (UNH), INRA/Université Clermont Auvergne, 63009 Clermont-Ferrand, France
}

Received 19 March 2019 - Accepted 2 May 2019

\begin{abstract}
Aging is characterized by a loss in muscle mass and function, which is defined as sarcopenia. It weakens individuals by increasing the risk of falls and altering their quality of life. The loss of muscle mass results from the age-related impairment of the anabolic effect of nutrients and insulin, which normally increase and decrease muscle protein synthesis and degradation rates respectively. Alterations in muscle protein metabolism have been related to the accumulation of body fat and intramyocellular lipids. In particular, some lipid species such as ceramides or diacylglycerols have been described as inhibitors of the insulin signaling pathway in different models. Accumulation of these molecules in skeletal muscle could result from a lowered buffering capacity of circulating fatty acids by adipose tissue in response to the meal, a reduction of mitochondrial oxidative capacities or chronic inflammation. However, some nutritional strategies have been identified to limit or prevent the accumulation of lipotoxic metabolites and to improve the sensitivity of muscle to nutrients or insulin.
\end{abstract}

Keywords: sarcopenia / muscle / lipids / protein metabolism / mitochondria / inflammation

Résumé - Infiltration intramusculaire de médiateurs lipidiques toxiques, un lien entre l'accumulation de masse adipeuse et la sarcopénie. La sarcopénie est définie comme une perte de masse et de fonction musculaires. Elle survient notamment au cours du vieillissement et fragilise les individus par augmentation du risque de chutes et une baisse de la qualité de vie. La perte de masse musculaire résulte d'une altération de l'équilibre entre les taux de synthèse et de dégradation des protéines contenues dans le tissu. On observe ainsi une altération de l'effet anabolique des nutriments (acides aminés) et de l'insuline qui permettent normalement de stimuler la synthèse et d'inhiber la dégradation des protéines. Les altérations du métabolisme protéique ont pu être reliées à l'accumulation globale de la masse adipeuse et à l'infiltration de lipides dans les muscles. En particulier, certaines espèces lipidiques telles que les céramides ou les diacylglycérols ont été décrites comme inhibitrices de la voie de signalisation de l'insuline dans différents modèles. Leur accumulation dans le muscle âgé pourrait résulter d'un défaut d'efficacité du tissu adipeux à tamponner l'excès d'acides gras circulants en réponse au repas, d'une réduction des capacités oxydatives mitochondriales musculaires ou de la présence d'une inflammation chronique. Certaines stratégies nutritionnelles ont néanmoins été mises en évidence pour lutter contre l'accumulation de métabolites lipotoxiques ou améliorer la sensibilité musculaire aux nutriments ou à l'insuline.

Mots clés : sarcopénie / muscle / lipides / métabolisme protéique / mitochondries / inflammation

\section{Introduction}

Age-related muscle mass reduction, as one aspect of sarcopenia, is a process characterized by a gradual loss of

\footnotetext{
"iv Contribution to the Topical Issue "Lipids in the elderly: needs, nutrition and physiopathology / Les lipides pour les seniors : besoins, alimentation et physiopathologie"

*Correspondence: frederic.capel@inra.fr
}

skeletal muscle and may lead to adverse health outcomes, such as falls, disability and poor quality of life (Van Ancum et al., 2018). Severely low muscle mass has been shown to be a risk factor of poor prognosis (Lin et al., 2018). This relatively precocious decline in lean body mass has been reported, starting after the third decade, even keeping weight stable, i.e. with a corresponding increase in fat mass (Fulton et al., 2009). Hence, with people aging, more fat will deposit as adipose tissue in different body parts especially in abdomen; body fat tending to redistribute from the subcutaneous toward the 
visceral depots (Stevens et al., 2010). Although this agerelated increase in total body fat has been demonstrated previously (Scott et al., 2018), little is known about its role in muscle mass loss. The presence of excess fat and reduced lean mass partially depicts the complex phenotype of sarcopenic obesity: in fact the hallmarks of this syndrome encompass an array of clinical aspects, mainly represented by functional impairment and mobility limitations. It is necessary to determine whether high body fat mass, is a risk factor for low skeletal muscle mass and impaired skeletal muscle metabolism (e.g. insulin sensitivity), which may lead to sarcopenia and decrease the quality of life in elderly people (Zhang et al., 2019). The present article illustrates the links between sarcopenia, the accumulation of fat mass and the implication of ectopic lipid deposition in skeletal muscle metabolic abnormalities, notably at the level of protein homeostasis and mitochondrial dysfunctions. Dietary interventions are with other factors (notably physical activity), crucial regulators of muscle mass and metabolism. Thus, a non-exhaustive list of easily applicable nutritional strategies, aiming at preserving muscle protein mass and metabolic homeostasis in elderly subjects is also presented.

\section{Association between body and muscle fat accumulation and sarcopenia}

Previous studies have revealed that fatty infiltration of the skeletal muscle predicted the drop in muscle strength in male elders who remained weight stable (Delmonico et al., 2009). Strength loss was reported to be associated with the increase in muscle fat infiltration, after adjustment for loss of muscle mass and initial values at baseline (Manini et al., 2007). Progressive fat accumulation in middle-aged or older adults may lead onto fibrosis and further impair muscle function and mobility. In addition, prior studies conducted in the geriatric population, demonstrating a detrimental role of fatty infiltration on functional parameters (Goodpaster et al., 2008). Visser et al. found that elders with larger mid-thigh muscle fat infiltration exhibited higher incidence of mobility disability over a 2.5 year follow-up period (Visser et al., 2005). In young- to middle-aged adults (24-48 years) with a range of body composition from lean to obese, muscle lipid infiltration was reported to be significantly associated with insulin resistance assessed by glucose clamp (Goodpaster et al., 1997). When sarcopenia was defined as muscle mass per unit weight, sarcopenic obese adults were found to have greater levels of insulin resistance than adults who were either solely sarcopenic or solely obese, regardless of sex (Lim et al., 2010). Another study reported that muscle fat infiltration was positively correlated with higher fasting plasma glucose and lower glucose tolerance in older adults (Prior et al., 2007). In turn, insulin resistance has been shown to prompt metabolic breakdowns of skeletal muscle, which may manifest clinically as sarcopenia. Furthermore, lipid storage and infiltration into muscle may also be a good marker of metabolic profile. All lipid species have different impacts on skeletal muscle metabolism. Ceramides and other toxic lipid species, such as diacylglycerols, have been identified as relevant mediators in the pathogenesis of lipid-induced insulin resistance in obesity and in type 2 diabetes (Amati et al., 2011; Brons and Grunnet, 2017).

\section{Ectopic fat deposition in skeletal muscle during aging: the link with adipose tissue}

\subsection{Role of adipose tissue in lipid storage: impact of aging}

White adipose tissue (WAT) plays a crucial role in lipid storage and distribution according to the nutritional status (Luo and Liu, 2016). In response to an increased insulin level in the blood, lipid storage is enhanced following meal ingestion, notably by the inhibition of lipolysis in adipocytes. On the contrary, fasting periods lead to the stimulation of lipolysis and the release of non-esterified fatty acid (NEFA). WAT's metabolism and ability to store and release NEFA also depends on its plasticity, i.e. the number (hyperplasia) and size (hypertrophy) of adipocytes (Arner et al., 2010). While smaller adipocytes secrete anti-inflammatory and insulin-sensitizing factors such as adiponectin, larger adipocytes produce proinflammatory factors (tumor necrosis factor alpha (TNF $\alpha$ ), leptin) and produce less adiponectin (Skurk et al., 2009). Differences were observed depending on the localization of WAT. Subcutaneous WAT (scAT) is more hyperplasic than visceral WAT (vAT) (Drolet et al., 2008). Furthermore, it was observed that the lipolytic activity of vAT correlated with its mass (Nielsen et al., 2004).

During aging, despite an increase in the percent of body fat and especially of vAT (Atlantis et al., 2008), the capacity of WAT to buffer plasma NEFA is impaired. A decreased ability to recruit new adipocytes was reported, mostly due to cellular senescence and decreased adipogenesis (Tchkonia et al., 2010). Furthermore, abdominal fat is a good predictor of insulin resistance in aging (Racette et al., 2006). TNF $\alpha$ secretion is also enhanced in the elderly, contributing to the chronic low-grade inflammation and impairment of insulin sensitivity. Insulin resistance in aging decreased the lipid storage capacity due to the lower inhibition of lipolysis, leading to a higher release of NEFA into the blood (Toth and Tchernof, 2000). These NEFA could then be stored in ectopic sites such as the liver and muscles, inducing metabolic abnormalities. Thus, adipose tissue metabolism might contribute to the impairments in muscle metabolism with aging through the secretion of pro-inflammatory factors and NEFA into the blood.

\subsection{Accumulation of lipids in muscles: imbalance between uptake and beta-oxidation}

The observation of lipid accumulation in muscles is not properly sufficient to explain an impairment of muscle function. Hence, it has been observed that athletes possess a high insulin sensitivity despite a significant increase of muscle total lipid content (Goodpaster et al., 2001). However, in aging, intermuscular fat and lipid deposition in skeletal muscle cells are increased and associated with the loss of muscle quality and function (Delmonico et al., 2009; Marcus et al., 2010). An hypothesis to consider is the imbalance between intracellular fat content and oxidative capacity. Indeed, age- 
related changes in mitochondrial capacity to oxidize FA is a crucial factor leading to skeletal muscle lipid accumulation and is an independent risk factor for weight gain and metabolic complications related to elevated body fat (Solomon et al., 2008). Mitochondrial dysfunctions with aging were described as a consequence of a decreased number of mitochondria, an increased damage of mitochondrial DNA, an increase in OXPHOS uncoupling and ROS production, and an impairment of mitochondrial biogenesis and turnover (Seo et al., 2016; Kauppila et al., 2017).

Taken together, increased muscle fat content in the elderly could be a consequence of an increase in fatty acid uptake due to an impaired storage in WAT and mitochondrial dysfunctions. Consequently, accumulation of lipid mediators might be a crucial element leading to the decrease in muscle mass and function. It has been recently demonstrated that the amount of lipotoxic mediators in muscle was correlated to impaired FA oxidative capacity in diabetic but not healthy volunteers (Broskey et al., 2018).

\section{Links between lipotoxicity and sarcopenia}

The loss of skeletal muscle mass and function is a consequence of a chronic reduction in net protein balance leading to a decrease in protein content. In this context, muscle protein synthesis cannot compensate muscle protein breakdown. Although all the mechanistic events and their relative contribution are not completely understood, several contributing factors were identified. Decreased amino acid intake, postprandial stimulation of muscle blood flow or increased splanchnic metabolism were observed with aging. Specific defects in the control of skeletal muscle metabolism were also described. Hence, the sensitivity of skeletal muscle to amino acid and insulin-dependent inhibition of protein breakdown and stimulation of protein synthesis (anabolic resistance) is lowered by age (Burd et al., 2013). It was demonstrated that the sensing of amino acids leading to activation of mTORC1 signaling pathway was impaired in old subjects (Cuthbertson et al., 2005). Accumulating evidences of the deleterious effects of the accumulation of toxic lipid mediators on skeletal muscle metabolism and insulin sensitivity strongly suggest that the loss of proteins could be, at least partially related to lipotoxicity. In vitro studies using muscle cells and rodent models of increased tissue lipotoxicity (i.e. studies in old animals, diet induced obesity, lipid infusion in mice or rats) were conducted to explore the links between lipids and muscle protein metabolism (Chavez et al., 2003; Zhou et al., 2007; Holland etal., 2011; Tardifet al., 2014). It was demonstrated that the exposure of $\mathrm{C} 2 \mathrm{C} 12$ myotubes to palmitic acid or ceramides decreased protein synthesis. This effect could be mediated by the activation of endoplasmic reticulum-stress mediated through EIF2 alpha (Tardif et al., 2014). In agreement with this, the decreased protein synthesis rate in skeletal muscle from old rats was associated to an accumulation of ceramides that were described to repress insulin signaling, notably at the level of Akt protein (Chavez et al., 2003; Tardif et al., 2014). The ubiquitin proteasome dependent proteolytic system is a major contributor of structural protein turnover. The system was hyper-activated in myotubes exposed to palmitic acid or in skeletal muscle from mice fed with a high fat diet which induced an accumulation of fat in muscle fibers (Zhou et al., 2007). The stimulation of protein catabolism was related to an increased expression of Murf1 and MAfbx, two key ubiquitin ligase enzymes involved in protein addressing to the proteasome (Zhou et al., 2007). These observations led to the conclusion that an excess of saturated fatty acid accumulated in lipotoxic fractions such as ceramides contributes to a chronic defect in the effect of insulin and nutrients on protein turnover leading to a net loss of muscle proteins. The alteration in insulin signaling by toxic lipids is mediated by the activation of serine/threonine kinases like c-jun N-terminal kinase (JNK), IкB kinase (IKK), and protein kinase $\mathrm{C}(\mathrm{PKC})$, triggering inactivation of the insulin receptor and its substrate. It could not be excluded that other factors such as oxidative stress or alteration in the secretion of protein by skeletal muscle or adipose tissue are also involved. Hence, a reduction in circulating adiponectin level triggered an excess of protein catabolism in a lipotoxic situation. In $\mathrm{C} 2 \mathrm{C} 12$ myotubes, adiponectin overexpression induced an inhibition of protein degradation, probably because of the stimulation of ceramide hydrolysis (Holland et al., 2011; Sharma and Holland, 2017).

Considering the insulin sensitizing and anti-inflammatory properties of adiponectin, it raised the question of the contribution of pro-inflammatory signals in sarcopenia, notably if associated with obesity (Kalinkovich and Livshits, 2017). Adiponectin plasma concentration is reduced with age and obesity (Arita et al., 1999; Vilarrasa et al., 2005). On the opposite, elevated CRP serum levels were retrieved in sarcopenic patients (Bano et al., 2017). Adipose tissue inflammation occurs with hypertrophy of adipocytes. The metabolic alterations induced by chronic inflammation in adipose tissue are now well described, promoting fatty acid and cytokine liberation with both local and endocrine effects in other organs. Adiponectin could decrease NFkb signaling which is a master regulator of inflammation (Tilg and Moschen, 2008). Future studies are still required to identify other secreted factors linked to sarcopenia and their contribution to the known mechanisms, such as lipotoxicity.

\section{Nutritional strategies for the management of sarcopenic obesity}

\subsection{Optimization of protein intake}

Several studies have suggested that reduction in skeletal muscle mass and consequent sarcopenia are facilitated by decreased nutrient intake, e.g. protein intake. The relationship between sarcopenic obesity and nutrition status, according to sex in Korean adults who were 60 years or older was previously examined (Oh et al., 2015). In this study, intake of nutrients associated with muscle loss (protein, vitamin $\mathrm{D}$, calcium, and vitamin C) was significantly different among the male groups, $i$. $e$. lower in subjects suffering from sarcopenic obesity as compared to controls. In addition, calcium and vitamin D intakes were insufficient in sarcopenic obese subjects regardless of sex. Hence, body composition changes seem related to nutrient intakes in older people with sarcopenic obesity.

Weight-loss management programs should be targeted at decreased fat mass and preservation of muscle mass in obese 
sarcopenic people. The main purpose of a previous study was to examine the effects of a diet with an increased amount of protein ( $1.2 \mathrm{~g} / \mathrm{kg}$ desirable body weight/day) on muscle mass and strength during weight-loss management for 3 months in sarcopenic obese older females (Muscariello et al., 2016). Precisely, sarcopenic obese older women were treated with a hypocaloric diet characterized by $1.2 \mathrm{~g} / \mathrm{kg}$ desirable body weight/day protein intake and compared to others who were administered with a hypocaloric diet characterized by $0.8 \mathrm{~g} / \mathrm{kg}$ desirable body weight/day protein intake. Overall, after 3 months' dieting, all groups showed a reduction in BMI and waist circumference, as expected. Moreover, diet treatment was able to reduce fat in both groups, while the arm-muscle area significantly decreased after 3 months only in the group receiving $0.8 \mathrm{~g} / \mathrm{kg}$ desirable body weight/day protein intake. Muscle mass index presented a significant reduction with the intervention in females consuming the lower protein amount, while in the higher protein intake group, muscle mass index significantly increased with the intervention. The results on physical strength, evaluated by handgrip test, indicated that there were no significant differences in the groups. Even though a trend for decreased physical strength (after $v s$. before intervention) was observed in the group receiving $0.8 \mathrm{~g} / \mathrm{kg}$ desirable body weight/day protein intake, females receiving $1.2 \mathrm{~g} / \mathrm{kg}$ desirable body weight/day protein intake showed a trend for increase (Muscariello et al., 2016). In a pilot study (Sammarco et al., 2017), obese sarcopenic subjects were randomly assigned to different nutritional interventions: hypocaloric diet plus placebo and hypocaloric high-protein diet (1.2-1.4 g/kg desirable body weight/day). Weight significantly decreased in both groups. Women with high-protein diet preserved lean body mass compared to low-calorie diet and improved significantly muscle strength. SF-36 test showed a significant change for general health after 4 months in the group receiving the high protein diet. Taken as a whole these data show that dietary protein enrichment may represent a protection from the risk of sarcopenia following a hypocaloric diet in obese older subjects (Sammarco et al., 2017). Moreover, a high whey protein- $(1.11 \pm 0.28 \mathrm{~g} / \mathrm{kg}$ body weight/day), leucine-, and vitamin D-enriched supplement compared with isocaloric control preserves appendicular muscle mass in obese older adults during a hypocaloric diet and resistance exercise program and might therefore reduce the risk of sarcopenia (Verreijen et al., 2015).

\subsection{Optimization of muscle metabolism using omega- 3 fatty acids}

Another nutritional strategy could aimed at stimulating protein anabolism through an improvement of insulin sensitivity, mitochondrial oxidative function and the limitation of inflammation. In this context several studies have suggested that omega-3 polyunsaturated fatty acids (PUFA) could be relevant candidates. It was found that the deleterious effect of toxic lipid mediators on muscle insulin sensitivity and FA oxidation could be improved by EPA and DHA (Capel et al., 2015; Pinel et al., 2015). A DHA-enriched diet led to the preservation of tibialis anterior muscle mass in mice after a 48h-fasting (Deval et al., 2016). Smith et al. showed that an omega-3 fatty acids supplementation in healthy adults and older adults with anabolic resistance improved muscle protein anabolic response and muscle protein rate through an increase in the phosphorylation (i.e. activation) of mTORSer2448 and p70S6KThr389 protein which are key activators of protein anabolism (Smith et al., 2011). Other studies in rodents have demonstrated the positive effect of omega-3 PUFA on mitochondrial functions and lipid oxidation (Lowell and Shulman, 2005; Cavaliere et al., 2016).

\section{Conclusions}

Accumulative evidences of the accumulation of lipid mediators in aged skeletal muscle and of the effects of these molecules on cell metabolism strongly support a link between intramuscular lipid infiltration and sarcopenia. Relevant mechanisms have been identified and some nutritional or lifestyle (such as exercise) strategies are already known to counteract some of it. Further studies are necessary, for example to identify biomarkers of the severity of sarcopenia in humans to determine how and when interventions should be proposed.

\section{References}

Amati F, Dube JJ, Alvarez-Carnero E, et al. 2011. "Skeletal muscle triglycerides, diacylglycerols, and ceramides in insulin resistance: Another paradox in endurance-trained athletes?" Diabetes 60 (10): 2588-2597.

Arita Y, Kihara S, Ouchi N, et al. 1999. "Paradoxical decrease of an adipose-specific protein, adiponectin, in obesity." Biochem Biophys Res Commun 257(1): 79-83.

Arner E, Westermark PO, Spalding KL, et al. 2010. "Adipocyte turnover: Relevance to human adipose tissue morphology." Diabetes 59(1): 105-109.

Atlantis E, Martin SA, Haren MT, Taylor AW, Wittert GA. 2008. "Lifestyle factors associated with age-related differences in body composition: The Florey Adelaide male aging study." Am J Clin Nutr 88(1): 95-104.

Bano G, Trevisan C, Carraro S, et al. 2017. "Inflammation and sarcopenia: A systematic review and meta-analysis." Maturitas 96: $10-15$.

Brons C, Grunnet LG. 2017. "Mechanisms in endocrinology: Skeletal muscle lipotoxicity in insulin resistance and type 2 diabetes: A causal mechanism or an innocent bystander?" Eur J Endocrinol 176(2): R67-R78.

Broskey NT, Obanda DN, Burton JH, Cefalu WT, Ravussin E. 2018. "Skeletal muscle ceramides and daily fat oxidation in obesity and diabetes." Metabolism 82: 118-123.

Burd NA, Gorissen SH, van Loon LJ. 2013. "Anabolic resistance of muscle protein synthesis with aging." Exerc Sport Sci Rev 41(3): 169-173.

Capel F, Acquaviva C, Pitois E, et al. 2015. "DHA at nutritional doses restores insulin sensitivity in skeletal muscle by preventing lipotoxicity and inflammation.” J Nutr Biochem 26(9): 949-959.

Cavaliere G, Trinchese G, Bergamo P, et al. 2016. "Polyunsaturated fatty acids attenuate diet induced obesity and insulin resistance, modulating mitochondrial respiratory uncoupling in rat skeletal muscle." PLoS One 11(2): e0149033.

Chavez JA, Knotts TA, Wang LP, et al. 2003. "A role for ceramide, but not diacylglycerol, in the antagonism of insulin signal transduction by saturated fatty acids." J Biol Chem 278(12): 10297-10303. 
Cuthbertson D, Smith K, Babraj J, et al. 2005. "Anabolic signaling deficits underlie amino acid resistance of wasting, aging muscle." FASEB J 19(3): 422-424.

Delmonico MJ, Harris TB, Visser M, et al. 2009. "Longitudinal study of muscle strength, quality, and adipose tissue infiltration." $\mathrm{Am} \mathrm{J}$ Clin Nutr 90(6): 1579-1585.

Deval C, Capel F, Laillet B, et al. 2016. "Docosahexaenoic acidsupplementation prior to fasting prevents muscle atrophy in mice." J Cachexia Sarcopenia Muscle 7(5): 587-603.

Drolet R, Richard C, Sniderman AD, et al. 2008. "Hypertrophy and hyperplasia of abdominal adipose tissues in women." Int J Obes 32(2): 283-291.

Fulton JE, Dai S, Steffen LM, Grunbaum JA, Shah SM, Labarthe DR. 2009. "Physical activity, energy intake, sedentary behavior, and adiposity in youth." Am J Prev Med 37(1 Suppl): S40-49.

Goodpaster BH, Thaete FL, Simoneau JA, Kelley DE. 1997. "Subcutaneous abdominal fat and thigh muscle composition predict insulin sensitivity independently of visceral fat." Diabetes 46(10): 1579-1585.

Goodpaster BH, He J, Watkins S, Kelley DE. 2001. "Skeletal muscle lipid content and insulin resistance: evidence for a paradox in endurance-trained athletes." J Clin Endocrinol Metab 86(12): $5755-5761$.

Goodpaster BH, Chomentowski P, Ward BK, et al. 2008. "Effects of physical activity on strength and skeletal muscle fat infiltration in older adults: A randomized controlled trial." J Appl Physiol (1985) 105(5): 1498-1503.

Holland WL, Bikman BT, Wang LP, et al. 2011. "Lipid-induced insulin resistance mediated by the proinflammatory receptor TLR4 requires saturated fatty acid-induced ceramide biosynthesis in mice." J Clin Invest 121(5): 1858-1870.

Kalinkovich A, Livshits G. 2017. "Sarcopenic obesity or obese sarcopenia: A cross talk between age-associated adipose tissue and skeletal muscle inflammation as a main mechanism of the pathogenesis." Ageing Res Rev 35: 200-221.

Kauppila TES, Kauppila JHK, Larsson NG. 2017. "Mammalian mitochondria and aging: An update." Cell Metab 25(1): 57-71.

Lim S, Kim JH, Yoon JW, et al. 2010. "Sarcopenic obesity: Prevalence and association with metabolic syndrome in the Korean Longitudinal Study on Health and Aging (KLoSHA)." Diabetes Care 33(7): 1652-1654.

Lin TY, Peng CH, Hung SC, Tarng DC. 2018. "Body composition is associated with clinical outcomes in patients with non-dialysisdependent chronic kidney disease.” Kidney Int 93(3): 733-740.

Lowell BB, Shulman GI. 2005. "Mitochondrial dysfunction and type 2 diabetes." Science 307(5708): 384-387.

Luo L, Liu M. 2016. "Adipose tissue in control of metabolism." $J$ Endocrinol 231(3): R77-R99.

Manini TM, Clark BC, Nalls MA, Goodpaster BH, Ploutz-Snyder LL, Harris TB. 2007. "Reduced physical activity increases intermuscular adipose tissue in healthy young adults." Am J Clin Nutr 85(2): 377-384.

Marcus RL, Addison O, Kidde JP, Dibble LE, Lastayo PC. 2010. "Skeletal muscle fat infiltration: impact of age, inactivity, and exercise." J Nutr Health Aging 14(5): 362-366.

Muscariello E, Nasti G, Siervo M, et al. 2016. "Dietary protein intake in sarcopenic obese older women." Clin Interv Aging 11: 133-140.

Nielsen S, Guo Z, Johnson CM, Hensrud DD, Jensen MD. 2004. "Splanchnic lipolysis in human obesity." J Clin Invest 113(11): $1582-1588$.

Oh C, Jho S, No JK, Kim HS. 2015. "Body composition changes were related to nutrient intakes in elderly men but elderly women had a higher prevalence of sarcopenic obesity in a population of Korean adults." Nutr Res 35(1): 1-6.

Pinel A, Rigaudiere JP, Laillet B, et al. 2015. "N-3PUFA differentially modulate palmitate-induced lipotoxicity through alterations of its metabolism in C2C12 muscle cells." Biochim Biophys Acta 1861 (1): 12-20.

Prior SJ, Joseph LJ, Brandauer J, Katzel LI, Hagberg JM, Ryan AS. 2007. "Reduction in midthigh low-density muscle with aerobic exercise training and weight loss impacts glucose tolerance in older men." J Clin Endocrinol Metab 92(3): 880-886.

Racette SB, Evans EM, Weiss EP, Hagberg JM, Holloszy JO. 2006. "Abdominal adiposity is a stronger predictor of insulin resistance than fitness among 50-95 year olds." Diabetes Care 29(3): 673-678.

Sammarco R, Marra M, Di Guglielmo ML, et al. 2017. "Evaluation of hypocaloric diet with protein supplementation in middle-aged sarcopenic obese women: A pilot study." Obes Facts 10(3): $160-167$.

Scott D, Cumming R, Naganathan V, et al. 2018. "Associations of sarcopenic obesity with the metabolic syndrome and insulin resistance over five years in older men: The concord health and ageing in men project." Exp Gerontol 108: 99-105.

Seo DY, Lee SR, Kim N, Ko KS, Rhee BD, Han J. 2016. “Age-related changes in skeletal muscle mitochondria: the role of exercise." Integr Med Res 5(3): 182-186.

Sharma AX, Holland WL. 2017. "Adiponectin and its hydrolaseactivated receptors." J Nat Sci 3(6): e396.

Skurk T, Alberti-Huber C, Hauner H. 2009. "Effect of conditioned media from mature human adipocytes on insulin-stimulated Akt/ PKB phosphorylation in human skeletal muscle cells: role of BMI and fat cell size." Horm Metab Res 41(3): 190-196.

Smith GI, Atherton P, Reeds DN, et al. 2011. "Dietary omega-3 fatty acid supplementation increases the rate of muscle protein synthesis in older adults: A randomized controlled trial." Am J Clin Nutr 93(2): 402-412.

Solomon TP, Marchetti CM, Krishnan RK, Gonzalez F, Kirwan JP. 2008. "Effects of aging on basal fat oxidation in obese humans." Metabolism 57(8): 1141-1147.

Stevens J, Katz EG, Huxley RR. 2010. “Associations between gender, age and waist circumference." Eur J Clin Nutr 64(1): 6-15.

Tardif N, Salles J, Guillet C, et al. 2014. "Muscle ectopic fat deposition contributes to anabolic resistance in obese sarcopenic old rats through eIF2alpha activation." Aging Cell 13(6): 1001-1011.

Tchkonia T, Morbeck DE, Von Zglinicki T, et al. 2010. "Fat tissue, aging, and cellular senescence." Aging Cell 9(5): 667-684.

Tilg H, Moschen AR. 2008. "Inflammatory mechanisms in the regulation of insulin resistance." Mol Med 14(3-4): 222-231.

Toth MJ, Tchernof A. 2000. "Lipid metabolism in the elderly." Eur J Clin Nutr 54(Suppl 3): S121-125.

Van Ancum JM, Pijnappels M, Jonkman NH, et al. 2018. "Muscle mass and muscle strength are associated with pre- and posthospitalization falls in older male inpatients: a longitudinal cohort study." BMC Geriatr 18(1): 116.

Verreijen AM, Verlaan S, Engberink MF, Swinkels S, de Vogel-van den Bosch J, Weijs PJ. 2015. "A high whey protein-, leucine-, and vitamin D-enriched supplement preserves muscle mass during intentional weight loss in obese older adults: a double-blind randomized controlled trial." Am J Clin Nutr 101(2): 279-286.

Vilarrasa N, Vendrell J, Maravall J, et al. 2005. "Distribution and determinants of adiponectin, resistin and ghrelin in a randomly selected healthy population." Clin Endocrinol (Oxf) 63(3): 329-335. 
Visser M, Goodpaster BH, Kritchevsky SB, et al. 2005. "Muscle mass, muscle strength, and muscle fat infiltration as predictors of incident mobility limitations in well-functioning older persons." J Gerontol A Biol Sci Med Sci 60(3): 324-333.

Zhang YJ, Fu SH, Wang JX, Zhao X, Zeng Q, Li XY. 2019. "Predictive value of percentage body fat in aging people with low muscle mass: A 2.2-year longitudinal study." Arch Gerontol Geriatr 82: 167-171.

Zhou Q, Du J, Hu Z, Walsh K, Wang XH. 2007. "Evidence for adipose-muscle cross talk: opposing regulation of muscle proteolysis by adiponectin and Fatty acids." Endocrinology 148(12): 5696-5705.

Cite this article as: Capel F, Pinel A, Walrand S. 2019. Accumulation of intramuscular toxic lipids, a link between fat mass accumulation and sarcopenia. OCL 26: 24. 